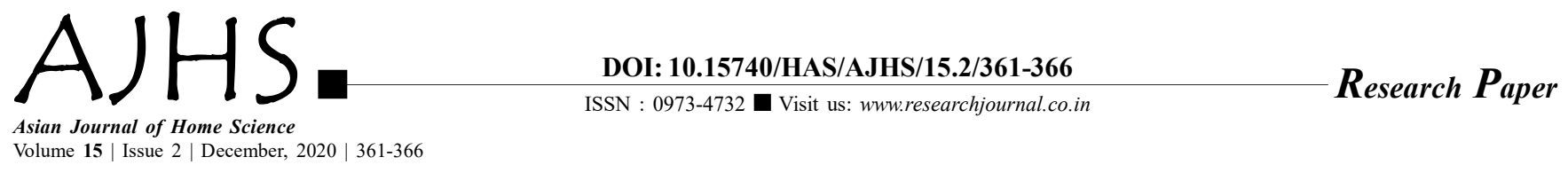

\title{
Health issues of pesticide applicators and their perception regarding pesticide application activities
}

\author{
Jayshree Suryatal and Madhuri Kulkarni
}

Received: 09.10.2020; Revised: 08.11.2020; Accepted: 25.11.2020

See end of the paper for authors' affiliations

Madhuri Kulkarni

Department of Resource

Management, College of

Community Science, Vasantrao

Naik Marathwada Krishi

Vidyapeeth, Parbhani (M.S.)

India

Email : profmadhuri@gmail.com
ABSTRACT : The present study was carried among 30 pesticide applicators from Marathwada region. Incidence of musculoskeletal problems of the pesticide applicators was identified by using Psychophysical techniques developed by Corlett and Bishop (1976). It is concluded that the majority of the pesticide applicants had light pain in neck (46.66), severe pain in shoulder $(83.33 \%)$ and upper back $(70 \%)$ while performing the task of pesticide application. Itching (70\%), skin rash $(86.66 \%)$ omitting and headache $(53.33 \%)$ were the other health issues reported by pesticide applicators.

KEY WORDS: Health issues, Musculoskeletal problems, Pesticide applicators

- HOW TO CITE THIS PAPER : Suryatal, Jayshree and Kulkarni, Madhuri (2020). Health issues of pesticide applicators and their perception regarding pesticide application activities. Asian J. Home Sci., 15 (2) : 361-366, DOI: 10.15740/HAS/AJHS/15.2/361-366. Copyright@ 2020: Hind Agri-Horticultural Society. 